\title{
Worker Productivity Loss Associated with Arthritis
}

WAYNE N. BURTON, M.D., ${ }^{1}$ CHIN-YU CHEN, Ph.D., ${ }^{2}$ ALYSSA B. SCHULTZ, M.S., ${ }^{2}$ DANIEL J. CONTI, Ph.D., ${ }^{3}$ GLENN PRANSKY, M.D. ${ }^{4}$ and DEE W. EDINGTON, Ph.D. ${ }^{2}$

\begin{abstract}
This study at a major financial services corporation sought to investigate the association of arthritis with on-the-job productivity, also termed "presenteeism." Using a modified version of the Work Limitations Questionnaire (WLQ) incorporated into a Health Risk Appraisal (HRA), 17,685 employees responded to the survey in 2002. Of the 16,651 respondents meeting inclusion criteria, 2,469 (14.8\%) reported having arthritis, and 986 (39.9\% of those with arthritis) also reported that they were under medical care and/or taking medication for arthritis. Employees with arthritis were older, predominantly female, and reported a higher number of comorbidities. Although all four domains of the WLQ (physical, time, mental, and output) were impacted by arthritis, the greatest productivity effect, as expected, was on physical work tasks. Health risks also play a role in the relationship between arthritis and presenteeism, with high-risk individuals reporting $\mathbf{7 \%}-\mathbf{1 0} \%$ additional loss of productivity compared to lowrisk individuals. In addition, those who reported receiving medication and/or treatment for arthritis had a $2.5 \%$ excess productivity loss independently attributed to their arthritis, which equals approximately $\$ 1,250$ per employee per year, or $\$ 5.4$ million to the corporation. This arthritis effect was discernible in those with low and moderate levels of health risk, but was not as evident in those with high health risks; in that group, health-associated decrements in productivity were much larger. Arthritis is associated with work productivity loss. Disease management programs should focus on pain management and arthritis-associated health risks and comorbidities in order to significantly decrease arthritis-related losses in on-the-job productivity. (Disease Management 2006;9:131-143)
\end{abstract}

\section{INTRODUCTION}

A RTHRITIS and other rheumatic conditions are the leading cause of disability among adults in the United States. ${ }^{1}$ In 2001, an estimated $33 \%$ of adults, about 70 million Americans, had arthritis or chronic joint symptoms. ${ }^{2}$ The costs of arthritis are expected to increase with the aging US population. The prevalence of arthritis increases with age and is greater in women than in men. ${ }^{3}$ The medical and lost productivity costs of arthritis and other rheumatic conditions in 1997 were estimated at \$86 billion. ${ }^{4}$ Arthritis and other rheumatic conditions have a substantial impact on health, as demonstrated by health-related quality of life mea-

\footnotetext{
${ }^{1}$ Department of Environmental and Occupational Sciences, University of Illinois at Chicago, Chicago Illinois.

${ }^{2}$ Health Management Research Center, University of Michigan, Ann Arbor, Michigan.

${ }^{3}$ Department of Psychology, DePaul University, Chicago, Illinois.

${ }^{4}$ Departments of Medicine and Family Medicine, University of Massachusetts Medical School, Worcester, Massachusetts.
} 
sures. ${ }^{5}$ Those with arthritis more commonly report fair or poor health, more days when physical health and/or mental health are not good, more unhealthy days, and more days of recent activity limitations. ${ }^{5}$

Osteoarthritis affects 21 million adults and is the most common form of arthritis in the United States; rheumatoid arthritis affects about 2.1 million adult Americans. ${ }^{3,6}$ Osteoarthritis causes a significant burden in lost productivity in the workplace, often leading to early retirement, and is second only to cardiovascular disease as the leading cause of work disability. ${ }^{7,8}$ Obesity is a significant risk factor for osteoarthritis. Research has shown that overweight and obesity precedes the development of osteoarthritis rather than being a consequence due to arthritis-related inactivity. ${ }^{9,10}$

Factors associated with disability in people with osteoarthritis include pain, psychosocial factors such as depressive symptoms, muscle weakness, poor aerobic exercise capacity, and severity of the disease on x-ray. Job-related arthritis is associated with workplace injury, with arthritis developing years later. Some states consider nonoccupational arthritis that is exacerbated by work to be job-related. The difficulties in determining what is work-related, work-exacerbated, or just reported in the workers compensation system makes these figures difficult to interpret. Yelin et al reported on the probability of work disability in patients with rheumatoid arthritis. As expected, as the disease worsened and its duration lengthened, the probability of disability increased. ${ }^{11-14}$

Leigh estimated job-related costs of osteoarthritis in the United States to be \$3.41-\$13.23 billion per year (1994 dollars). ${ }^{15}$ About $51 \%$ of the job-related arthritis costs are medical, and $49 \%$ are from lost productivity at work. ${ }^{15} \mathrm{~A}$ more recent study by Ricci et al estimated the lost productive time due to arthritis in the US workforce to be $\$ 7.11$ billion. A disproportionate amount of this cost was due to workers who had pain exacerbations or flare-ups. ${ }^{16}$

Arthritis is considered by many as an age-related disease that causes relatively minor discomfort and pain. Yet, arthritis has serious economic consequences because it is a common chronic disease in the working population and once workers develop this disease, it can affect job productivity for the remainder of their careers. Limitations in the performance of simple tasks due to pain can lead to permanent work disability. ${ }^{17}$

For a nonfatal disabling disease such as arthritis, the lifetime economic consequence of disability and lost productivity may greatly exceed the healthcare costs. We have previously reported on the impact of several medical conditions, including arthritis, on worker productivity, also termed "presenteeism."18 The purpose of this study is to more thoroughly evaluate the impact of arthritis on work-related productivity.

\section{METHODS}

\section{Study population}

The population in this study was employed by one of the largest financial services companies in the United States, with employees located in 29 states. Approximately 73,500 people were employed, $70 \%$ of whom were female, during the third quarter of 2002. The mean age of the workforce was approximately 38 years. The majority of employees performed clerical jobs such as accounting, receiving/sorting financial statements, customer service, and a variety of other financial services tasks.

\section{Health Risk Appraisal}

In July 2002, a Health Risk Appraisal (HRA) questionnaire was distributed to all employees from the Corporate Medical Department. This HRA was based on Healthier People, Version 4.0, 1991 (Carter Center of Emory University, Atlanta, GA, 1991) and enhanced in cooperation with the University of Michigan's Health Management Research Center (UMHMRC; Ann Arbor, MI). Each participant completing the HRA received an individualized report summarizing their health risks and suggestions for health improvement directly from the UMHMRC. A Mayo Clinic Self-Care book (retail value \$16.95) was provided to employees completing the HRA.

In addition to asking employees about the presence of biological and lifestyle health risk factors, the HRA included the following ques- 
tion about the presence of several chronic diseases: "Has your doctor ever told you that you have had any of the following?" The list of chronic conditions included seasonal allergies, asthma, arthritis, back pain, cancer (any type), depression, diabetes mellitus, heartburn, heart disease, high cholesterol, hypertension, irritable bowel syndrome, kidney disease, menopause, and osteoporosis. Additionally, respondents were asked whether they were either being treated by a physician or currently taking medications for those conditions for which they reported "yes." This study was conducted in accordance with the University of Michigan's Institutional Review Board.

\section{Worker productivity assessment}

The 25-item self-administered Work Limitations Questionnaire (WLQ) was developed and validated to measure health-related decrements in job-related productivity loss. ${ }^{19}$ It has also been validated in a population of 230 workers with osteoarthritis to assess the impact of osteoarthritis on worker productivity. ${ }^{20}$ The WLQ measures four domains of on-the-job productivity: physical work activities, time management, mental/interpersonal activities, and overall output or productivity.

An eight-item brief version of the WLQ was included in the HRA to assess the health-related impact of chronic medical conditions such as arthritis on work performance. ${ }^{18,21}$ These questions evaluated the percentage of time at work that an emotional or physical problem interfered with one or more of the four work domains. Employees were asked to base their responses on their previous 2 weeks of work and to rate any impairment as "All of the Time (100\%)," "Most of the Time," "Half of the Time (50\%)," "Some of the Time," "None of the Time $(0 \%)$ " or "Does Not Apply to My Job." For each item, scores of $0,1,2,3$, and 4 were assigned to answers of "none of the time $(0 \%)$, , "some of the time," "half of the time (50\%)," "most of the time," and "all of the time (100\%)," respectively. An answer of "does not apply to my job" was considered a missing answer.

The WLQ was scored as four subscales from two questions related to each of the four domains. An overall WLQ score was calculated by averaging the four subscale scores. In this way, the score has a range of 0 to 4 , and each score of 1 represents a $25 \%$ loss of self-reported productivity. The percentage of productivity loss associated with health risks was estimated directly by multiplying the WLQ score by $25 \%{ }^{21}$ To study the odds of reporting any work limitation in work domains or overall work, dichotomous scores (yes/no) for each subscale and the overall work limitation were established.

\section{Short-term disability}

All employees in this financial services corporation are eligible to file short-term disability (STD) claims. STD is managed initially by the corporation and begins after 5 consecutive workdays off and may continue for up to 6 months. All STD claims include diagnostic codes (ICD-9 codes) in addition to the number of days absent. Arthritis events are identified by ICD-9 codes 710-719.9.

\section{Statistical analysis}

A multivariate, logistic regression model was constructed to study the odds of reporting for each WLQ subscale and overall work limitation, with age, gender, health risks, and each medical condition as independent variables. A second multiple regression model was used to calculate the percent productivity loss for each group due to arthritis by controlling for demographics, health risks, and the other health conditions. This analysis utilized a generalized linear model in SAS with a negative binomial distribution. Then, the excess work loss was calculated by subtracting each group's percent productivity loss from that of the reference group (no arthritis). All analyses were conducted using SAS 8.0 software (SAS Institute Inc., Cary, NC).

\section{RESULTS}

In July 2002, 73,456 employees were sent an HRA; of these, 17,685 were returned ( $24 \%$ response rate). To meet the criteria for inclusion, the respondent had to be listed in the corporation's personnel database and have completed 
all the WLQ questions. As a result of these selection criteria, 1,034 (1\%) questionnaires were excluded from the study, leaving a total of 16,651 respondents. The response rate is typical of those reported for HRAs in the research literature. ${ }^{22,23}$

The average age of respondents included in the study was 38.9 years and $76 \%$ were female. A total of 2,469 (14.8\%) responded "yes" to having arthritis; among them, 986 (5.9\%) of respondents reported that they were under medical care for and/or taking medication for arthritis. Table 1 compares employees with and without arthritis. Those who reported having arthritis are further split into those who reported receiving care and/or medication for arthritis and those who did not. On average, employees with arthritis were older (46.2 vs. 37.6 years) and more likely to be female $(83 \%$ vs. $75 \%$ ) than those without arthritis. After adjusting for demographics and other risks and conditions, obesity (Body Mass Index $[\mathrm{BMI}] \geq$ 30), using medication to relax, fair or poor perception of health, high stress, and the presence of cancer, diabetes, or heart disease were statistically significantly more common among employees with arthritis compared to those without. Of employees reporting arthritis, 39\% were obese (BMI $\geq 30), 25 \%$ reported the use of medication to relax, $22 \%$ reported fair or poor health, and $42 \%$ had high stress. Employees with arthritis were significantly more likely to be in the high-risk group (5+ health risk factors) than employees without arthritis $(p<0.0001)$. The average number of health risk factors for employees with arthritis was 3.06, in comparison with 2.24 for employees without arthritis $(p<0.0001)$.

When dividing the employees with arthritis into those who do and do not receive medical care and/or medication for the condition, there are also some significant differences. These two

\begin{tabular}{|c|c|c|c|c|c|}
\hline & $\begin{array}{c}\text { All, } \\
\mathrm{N}=16,651\end{array}$ & $\begin{array}{l}\text { No arthritis, } \\
\mathrm{N}=14,182\end{array}$ & $\begin{array}{c}\text { Arthritis } \\
\text { (all) } \\
\mathrm{N}=2,469\end{array}$ & $\begin{array}{c}\text { Arthritis } \\
\text { (no care), } \\
\mathrm{N}=1,483\end{array}$ & $\begin{array}{r}\text { Arthritis } \\
\text { (med/care), } \\
\mathrm{N}=986\end{array}$ \\
\hline \multicolumn{6}{|l|}{ Demographics } \\
\hline Female* & $76 \%$ & $75 \%$ & $83 \%$ & $81 \%$ & $87 \%$ \\
\hline Average age $e^{* *}$ & 38.9 & 37.6 & 46.2 & 45.4 & 47.4 \\
\hline \multicolumn{6}{|l|}{ Health risks } \\
\hline High stress ${ }^{* *}$ & $35 \%$ & $34 \%$ & $42 \%$ & $40 \%$ & $44 \%$ \\
\hline Obese $(\mathrm{BMI} \geq 30)^{* *}$ & $27 \%$ & $25 \%$ & $39 \%$ & $35 \%$ & $44 \%$ \\
\hline Physical activity $<1 /$ wk & $29 \%$ & $28 \%$ & $34 \%$ & $32 \%$ & $37 \%$ \\
\hline Life dissatisfaction & $28 \%$ & $27 \%$ & $32 \%$ & $32 \%$ & $30 \%$ \\
\hline High blood pressure & $18 \%$ & $16 \%$ & $30 \%$ & $27 \%$ & $36 \%$ \\
\hline Use medication to relax ${ }^{* *}$ & $17 \%$ & $15 \%$ & $25 \%$ & $21 \%$ & $32 \%$ \\
\hline Perception of health (fair or poor)* & $16 \%$ & $15 \%$ & $22 \%$ & $18 \%$ & $27 \%$ \\
\hline Job dissatisfaction & $14 \%$ & $14 \%$ & $16 \%$ & $16 \%$ & $15 \%$ \\
\hline High cholesterol $^{* * *}$ & $8 \%$ & $7 \%$ & $14 \%$ & $12 \%$ & $18 \%$ \\
\hline Current smokers & $10 \%$ & $10 \%$ & $11 \%$ & $11 \%$ & $11 \%$ \\
\hline Safety belt usage $<90 \%$ & $11 \%$ & $11 \%$ & $11 \%$ & $11 \%$ & $10 \%$ \\
\hline Alcoholic drinks $>14 /$ wk & $2 \%$ & $2 \%$ & $2 \%$ & $2 \%$ & $2 \%$ \\
\hline \multicolumn{6}{|l|}{ Overall risk status ${ }^{* *}$} \\
\hline $0-2$ risks & $59 \%$ & $62 \%$ & $44 \%$ & $48 \%$ & $39 \%$ \\
\hline 3-4 risks & $26 \%$ & $25 \%$ & $32 \%$ & $31 \%$ & $34 \%$ \\
\hline $5+$ risks & $15 \%$ & $13 \%$ & $23 \%$ & $20 \%$ & $28 \%$ \\
\hline Average number of risks** & 2.36 & 2.24 & 3.06 & 2.86 & 3.36 \\
\hline \multicolumn{6}{|c|}{$\begin{array}{l}\text { aRisk analyses controlled for demographics, other risks, and other conditions. } \\
{ }^{*} p<0.05 \text { significant difference between no arthritis, arthritis no-care, and arthritis med/care groups. } \\
{ }_{* *} p<0.05 \text { significant difference between no arthritis and arthritis group. Arthritis no-care and arthritis med/care } \\
\text { groups are not significantly different from each other. } \\
\text { ***p }<0.05 \text { significant difference between no arthritis and arthritis med/care group. Arthritis no-care group also } \\
\text { significantly different from arthritis med/care group. } \\
\text { Med/care, under medical care for and/or taking medication for arthritis; BMI, Body Mass Index; wk, week. }\end{array}$} \\
\hline
\end{tabular}


groups are significantly different in the percentage of women $(81 \%$ in no-care group, $87 \%$ in med/care group), in perceiving their health as fair or poor $(18 \%$ in no-care group, $27 \%$ in $\mathrm{med}$ (care group), and in having high cholesterol (12\% in no-care group, $18 \%$ in med/care group).

Participants had an opportunity to report 15 different health conditions on the HRA, one of which was arthritis. Table 2 shows the percentages of these conditions by the different study populations. Similar to the number of health risks, the number of other health conditions in employees with arthritis was 1.49 , in comparison with 0.69 for employees without arthritis $(p<$ 0.0001). After controlling for demographics, health risks, and other health conditions, employees with arthritis who received medication and/or medical care had significantly greater incidence of the following health conditions compared to employees without arthritis: seasonal allergy, asthma, back pain, depression, heart burn (acid reflux), high cholesterol, menopause, and osteoporosis. Furthermore, the med/care arthritis group had significantly more other conditions that required medication or medical care (2.24 vs. 0.98 for no-care group and 0.69 for those without arthritis). Sixty-one percent of the med/care arthritis group reported having one or more other conditions, compared to $27 \%$ of the no-care group $(p<0.05)$.

The prevalence of arthritis in employees in different age groups is shown in Figure 1. For employees under age 40 , the prevalence of arthritis is less than $10 \%$, whereas it exceeds $40 \%$ for employees age $60-64$. For all age categories combined, $40 \%$ of employees reporting they had been diagnosed with arthritis were either under medical care and/or taking medication for their arthritis $(6 \%$ of employees in the med/care group out of $14.8 \%$ of employees reporting an arthritis diagnosis).

\section{Work limitations}

The impact of arthritis on work limitation is summarized in Figure 2, which shows the re-

\begin{tabular}{|c|c|c|c|c|c|}
\hline & $\begin{array}{c}\text { All, } \\
\mathrm{N}=16,651\end{array}$ & $\begin{array}{l}\text { No arthritis, } \\
\mathrm{N}=14,182\end{array}$ & $\begin{array}{c}\text { Arthritis } \\
\text { (all) } \\
\mathrm{N}=2,469\end{array}$ & $\begin{array}{c}\text { Arthritis } \\
\text { (no care), } \\
\mathrm{N}=1,483\end{array}$ & $\begin{array}{c}\text { Arthritis } \\
\text { (med/care), } \\
\mathrm{N}=986\end{array}$ \\
\hline \multicolumn{6}{|l|}{$\begin{array}{l}\text { Health conditions that require } \\
\text { medication or medical care }\end{array}$} \\
\hline Seasonal allergy ${ }^{* * *}$ & $22 \%$ & $21 \%$ & $30 \%$ & $21 \%$ & $43 \%$ \\
\hline Asthma $a^{* * *}$ & $5 \%$ & $5 \%$ & $8 \%$ & $5 \%$ & $13 \%$ \\
\hline Back pain $* * *$ & $7 \%$ & $5 \%$ & $17 \%$ & $6 \%$ & $34 \%$ \\
\hline Cancer & $2 \%$ & $1 \%$ & $3 \%$ & $2 \%$ & $4 \%$ \\
\hline Depression ${ }^{* *}$ & $9 \%$ & $8 \%$ & $15 \%$ & $11 \%$ & $20 \%$ \\
\hline Diabetes & $3 \%$ & $3 \%$ & $5 \%$ & $4 \%$ & $6 \%$ \\
\hline Heart burn (acid reflex) ${ }^{* * *}$ & $9 \%$ & $7 \%$ & $17 \%$ & $11 \%$ & $27 \%$ \\
\hline Heart disease & $1 \%$ & $1 \%$ & $3 \%$ & $2 \%$ & $4 \%$ \\
\hline High cholesterol $^{*}$ & $8 \%$ & $7 \%$ & $15 \%$ & $10 \%$ & $21 \%$ \\
\hline High blood pressure & $11 \%$ & $9 \%$ & $21 \%$ & $17 \%$ & $28 \%$ \\
\hline Irritable bowel syndrome & $3 \%$ & $2 \%$ & $5 \%$ & $3 \%$ & $8 \%$ \\
\hline Kidney disease & $0 \%$ & $0 \%$ & $1 \%$ & $0 \%$ & $1 \%$ \\
\hline Menopause ${ }^{* * *}$ & $8 \%$ & $6 \%$ & $19 \%$ & $13 \%$ & $28 \%$ \\
\hline Osteoporosis ${ }^{* * *}$ & $1 \%$ & $1 \%$ & $5 \%$ & $2 \%$ & $8 \%$ \\
\hline Average number of health conditions ${ }^{* * *}$ & 0.81 & 0.69 & 1.49 & 0.98 & 2.24 \\
\hline Having one or more other conditions $s^{* * *}$ & $21 \%$ & $18 \%$ & $40 \%$ & $27 \%$ & $61 \%$ \\
\hline \multicolumn{6}{|c|}{$\begin{array}{l}{ }^{a} \text { Analyses controlled for demographics, overall risk status, and other conditions. } \\
{ }^{*} p<0.05 \text { significant difference between no arthritis, arthritis no-care, and arthritis med/care groups. } \\
* * x<0.05 \text { significant difference between no arthritis and arthritis group. Arthritis no-care and arthritis med/care } \\
\text { groups are not significantly different from each other. } \\
\text { significantly different from arthritis med/care group. } \\
\text { Med/care, under medical care for and/or taking medication for arthritis. }\end{array}$} \\
\hline
\end{tabular}




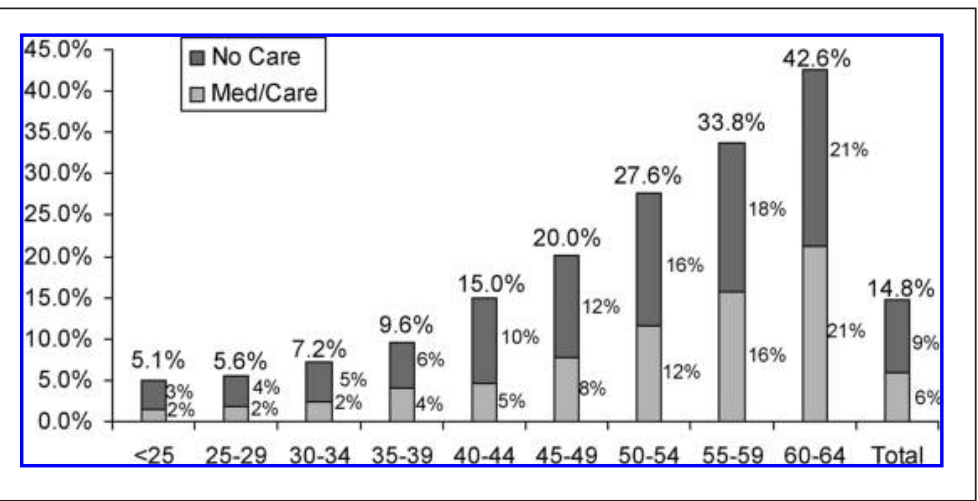

FIG. 1. Prevalence of self-reported arthritis and age for employees with arthritis, with and without medication and/or medical care.

sults of multiple logistic regression controlling for demographics, other health conditions, and health risks. The odds of reporting any work impairment for each of the four WLQ domains and overall are reported in Figure 2. The two arthritis groups (no-care and med/care groups) were compared with employees who did not report having arthritis as well as with each other, controlling for age, gender, health risks, and other health conditions. Compared to employees without arthritis, the group of employees with arthritis but not receiving care or medication for the condition had significantly higher odds of reporting a work limitation for all four domains (Odds Ratio [OR] for time, 1.23; physical, 1.25; mental, 1.21; output, 1.14) and overall $(\mathrm{OR}=1.28)$. The arthritis group receiving medication and/or care was significantly different from employees without arthritis for both the physical $(\mathrm{OR}=1.53)$ and output $(\mathrm{OR}=1.24)$ domains, as well as any limitation overall $(\mathrm{OR}=1.42)$. Furthermore, the arthritis med/care group had significantly higher odds of reporting a physical work limitation compared to the arthritis group receiving no medication or care (1.53 arthritis med/care vs. 1.25 arthritis no-care).

Table 3 shows the WLQ scores and the corresponding percent productivity loss, which is calculated by multiplying the WLQ score by $25 \%$. The WLQ and, subsequently, the percent productivity loss increases from the no arthritis group (score of 0.629) to the arthritis no-care group (0.653) to the arthritis med/care group (0.730). In each group of employees (no arthritis, arthritis no-care, and arthritis med/care), those with more health risks also have more productivity loss.

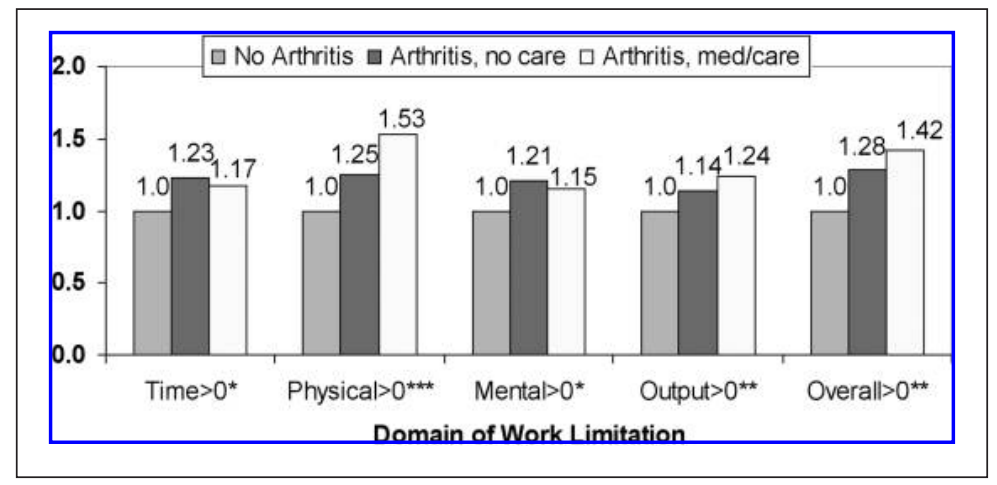

FIG. 2. Odds of having work limitations associated with arthritis and with/or without medication or under medical care (controlling for demographics, health risks, and other health conditions). ${ }^{*} p<0.01$ between no arthritis and arthritis no-care groups. ${ }^{* *} p<0.01$ comparing both arthritis no-care and arthritis med/care groups to no arthritis group. ${ }^{* *} p<0.01$ All three groups are significantly different from each other. 


\begin{tabular}{|c|c|c|c|}
\hline Arthritis status & $\begin{array}{l}\text { Risk } \\
\text { category }\end{array}$ & WLQ score & $\begin{array}{l}\text { Percentage productivity loss } \\
\quad(W L Q \text { score } \times 25 \%)\end{array}$ \\
\hline \multirow{4}{*}{ No arthritis** } & All & 0.629 & $15.7 \%$ \\
\hline & $0-2$ risks & 0.448 & $11.2 \%$ \\
\hline & 3-4 risks & 0.668 & $16.7 \%$ \\
\hline & $5+$ risks & 0.866 & $21.7 \%$ \\
\hline \multirow[t]{4}{*}{ Arthritis no care ${ }^{* *}$} & All & 0.653 & $16.3 \%$ \\
\hline & $0-2$ risks & 0.458 & $11.4 \%$ \\
\hline & $3-4$ risks & 0.703 & $17.6 \%$ \\
\hline & $5+$ risks & 0.897 & $22.4 \%$ \\
\hline \multirow[t]{4}{*}{ Arthritis med/care ${ }^{* *}$} & All & 0.730 & $18.2 \%$ \\
\hline & $0-2$ risks & 0.587 & $14.7 \%$ \\
\hline & $3-4$ risks & 0.764 & $19.1 \%$ \\
\hline & $5+$ risks & 0.880 & $22.0 \%$ \\
\hline
\end{tabular}

Figure 3 shows the impact of health risks on worker productivity among those with arthritis. Comparisons were made across the three study groups by health risk category. Results are shown as percentage of productivity loss, which is calculated by multiplying the WLQ score by $25 \%$.

While arthritis is certainly associated with increased on-the-job productivity loss, health risks also play a role. All comparison groups except the low-risk arthritis no-care group have significantly greater work loss compared to the low-risk group of employees without arthritis. Health risks are clearly an important factor to consider when examining presenteeism. One important finding is that employees with arthritis (whether or not they are being treated for it) who maintain low health risks have lower productivity loss compared to those without arthritis but in the medium- or high-risk category. The highest reported productivity losses are in the two arthritis groups with high health risks $(22.4 \%$ in no-care group, $22.0 \%$ in med/care group). The non-arthritis group with high risks also has high levels of reported productivity loss $(21.7 \%)$, compared to those with low risks.

After controlling for demographics, risk level, and other health conditions, the overall productivity loss of employees in the nonarthritis, no-care, and receiving care groups are

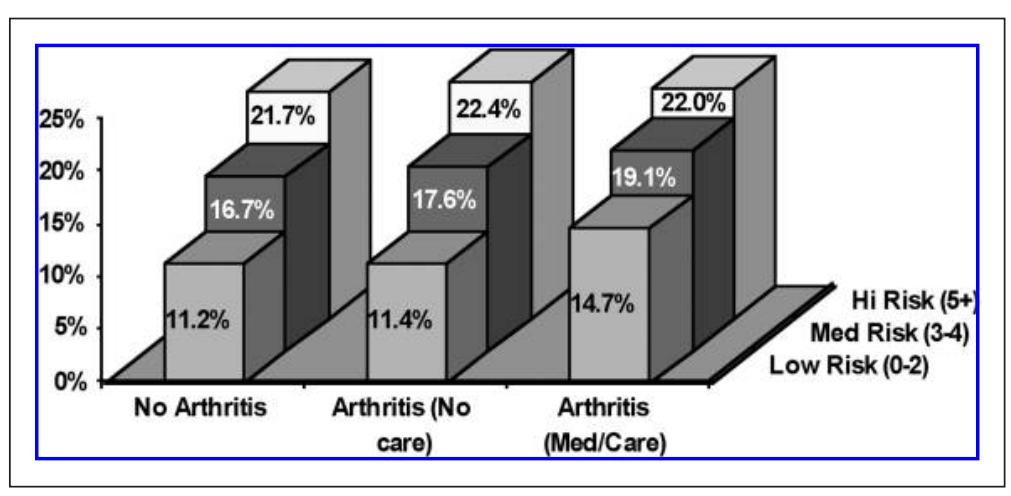

FIG. 3. Percent productivity loss associated with arthritis and health risk status. All except low-risk arthritis no-care group are $p<0.001$ compared to low-risk no arthritis group. 
$15.7 \%, 16.3 \%$, and $18.2 \%$, respectively. Results showed that the arthritis no-care group has similar work loss compared to the non-arthritis group $(16.3 \%$ compared to $15.7 \%)$. The group of employees with arthritis who reported receiving medical treatment or medication had a work loss of $18.2 \%$. Subtracting the $15.7 \%$ productivity loss of the reference group (no arthritis) from the $18.2 \%$ productivity loss of the arthritis med/care group results in an excess productivity loss of $2.5 \%$ compared to the non-arthritic employees.

\section{DISCUSSION}

Employees who report having medically treated arthritis were found to be older, had more comorbidities, and had a greater number of health risk factors than other employees. The prevalence of arthritis increases with age. In all, $14.8 \%$ of employees report having arthritis. Approximately $40 \%$ of these employees report the use of medication or medical care for their arthritis. This percentage is fairly consistent for all age groups until approximately age 55, when $46 \%$ of arthritis employees receive care. Among the oldest age group in our study (60-64 years), 50\% of employees with arthritis report receiving care and/or medication for the condition (Fig. 1). These data suggest that there is an opportunity for disease management programs to educate employees about receiving appropriate treatment for their arthritis.

Even after controlling for demographics, health risks, and other health conditions, employees with arthritis who were not receiving treatment had significantly increased risk for limitations in all four WLQ domains, as well as any limitation overall. Arthritic employees who were receiving treatment had an increased risk of limitation in their ability to do physical aspects of the job and in their output compared to those without arthritis. Arthritic employees receiving medication or care were significantly more likely to have a physical work limitation compared to arthritic employees who did not receive care.

Interestingly, those who reported having arthritis but not receiving care had significantly higher odds of work limitations in the time and mental/interpersonal domains of the WLQ compared to employees without arthritis. The group of employees with arthritis who received treatment did not show significantly higher odds of limitation in these two WLQ domains. It may be that medication and/or other forms of medical treatment for arthritis help employees to be more productive in certain aspects of their job compared to employees not receiving care for their arthritis. In one of the domainsthe physical aspect-employees receiving treatment still have significantly higher odds of a work limitation compared to employees not receiving treatment. Those who do seek medication and/or treatment may have a more severe form of arthritis which, not surprisingly, significantly impacts their ability to perform physical tasks. Given the prevalence data presented by age, younger employees may feel that they are "too young" to seek treatment for their arthritis. As noted, it wasn't until age 60 that at least $50 \%$ of arthritic employees received care or medication for the condition. There may be an opportunity for the corporate medical department to educate employees on available treatments for arthritis and to encourage employees to seek appropriate care.

As expected, our study demonstrated that the greatest on-the-job productivity effect of arthritis was on physical work tasks, where those with arthritis (med/care) were 1.5 times as likely to self-report productivity problems as workers without arthritis (Fig. 2). The risk for having problems with work output and the overall measure of work limitation were also significantly elevated, though as would be expected, less so than for physical problems. The pattern is consistent with expected physical limitations that are the hallmark of this condition.

In their validation study of 230 employees with osteoarthritis, the authors of the WLQ found that the Physical Demand scale scores varied with the level of arthritis pain, joint stiffness, and functional limitations. ${ }^{20}$ Physical Demand scores were affected by the severity of osteoarthritis and comorbid conditions. The Time Management Scale was associated with the severity of osteoarthritis. The Mental-Interpersonal Demand Scale was related to arthritis pain and stiffness, but there was no significant 
difference between controls and patients with osteoarthritis. The Output Demands scale was associated with the amount of pain and stiffness, but not with the degree of functional limitations.

Health risks also play a role in the relationship between arthritis and work impairment. As can be seen in Figure 3, those with arthritis (both no-care and med/care groups) who maintain a low level of health risk ( $0-2$ risk factors) have a smaller percentage of on-the-job work loss than those without arthritis, but who are medium (3-4 risks) or high (5+ risks) risk. The literature has shown that worksite health promotion programs can be successful in helping employees to reduce their health risks. ${ }^{24-26}$ Disease management programs combined with health promotion programs could possibly result in improved work performance, even among those with chronic conditions such as arthritis.

Employees who reported receiving treatment for their arthritis also reported a greater number of comorbidities than their fellow employees. Some of these are not surprising, such as back pain and osteoporosis. Twenty percent of employees with arthritis who were receiving treatment or medication for their condition also reported depression. This compares with $8 \%$ of employees without arthritis and $11 \%$ of employees with arthritis not receiving care. One study of arthritis and depression found that the two conditions often occur together. ${ }^{27}$ Furthermore, these investigators found that in an older population, successful treatment of depression also decreased pain and improved functional status and quality of life among subjects. ${ }^{27}$ Disease management programs aimed at helping employees deal with their arthritis should be cognizant of the comorbidities which they may have.

Employees with arthritis who are receiving medication or treatment for their condition have $2.5 \%$ excess work loss compared to employees without arthritis. Employees with arthritis who did not receive care had a similar level of work loss compared to employees without arthritis, even after controlling for health risk level, other health conditions, and demographics. The $2.5 \%$ excess productivity loss found here is similar to results found in a previous study in this same population. ${ }^{21}$ In that cross-sectional study of one-time HRA participants, each additional risk factor that employees had was associated with a $2.4 \%$ loss in self-reported productivity. A second study of productivity change associated with health risk change found that adding or subtracting health risks over time resulted in a $1.9 \%$ change in selfreported productivity loss. ${ }^{28}$ These three results combined lead to the conclusion that each additional risk factor or health condition is associated with approximately $2 \%$ more productivity loss compared to low-risk employees without health conditions. It may be advantageous to elevate health conditions to the same status as health risks traditionally examined in HRAs. In this instance, one health conditionarthritis-shows approximately the same level of work loss as the average health risk (such as smoking or obesity).

The criteria for identifying workers with arthritis in our study was similar to other population-based investigations that have attempted to identify all workers with arthritis requiring medical treatment. ${ }^{1,29}$ Alternative "objective" measures of osteoarthritis, such as range of motion or radiographic changes do not correlate well with functional or clinically-important impacts. ${ }^{30,31}$ The prevalence of self-reported arthritis in this study was similar to other surveys. ${ }^{32}$ These studies have demonstrated an increased prevalence of arthritis with age, female gender and more comorbidities. However, symptomatic arthritis is not confined to the elderly; it has a substantial impact on working populations as well. ${ }^{33}$

Other studies also have demonstrated the negative impact of arthritis on work productivity. Muchmore et $\mathrm{al}^{34}$ analyzed health claims, disability payments, and productivity data from a sample of 36,776 workers, and found an average of over $\$ 350$ excess costs for work absence in those with self-reported, medically treated arthritis. However, unlike the current study, they did not demonstrate a significant impact on on-the-job productivity, likely due to the insensitivity of the single question measure employed. Similar findings were noted in the study by Kessler et al, ${ }^{29}$ where one third of those with arthritis had some self-reported limitation in work function, with an 
odds ratio of 1.7. However, these prior studies did not specify the actual type of work limitations encountered due to these conditions. Although the incidence of arthritis increases with age, and presumably the severity increases with age as well, the percentage of those with arthritis who had work limitations was not age related in the current study. This is most likely due to the healthy worker effect, where those with more severe or progressive disease leave the workplace, often through earlier retirement. ${ }^{17,35}$

Based on the current study, the cost of lost workplace productivity is estimated at $\$ 1,250$ per employee with arthritis per year $(\$ 50,000$ salary $\times 2.5 \%$ lost productivity). Assuming that this study sample is representative of the entire study population, $5.9 \%$ of all employees have arthritis for which they receive treatment or medication. The total cost of their lost workplace productivity is estimated at \$5.4 million per year $(\$ 1,250$ per employee per year $\times 5.9 \%$ of employees $\times 73,500$ employees).

We also examined STD claims for this same employee population in 2002 utilizing ICD-9 codes 710-719.9 and identified 218 employees with at least one STD event for arthritis. In 2002, the corporation experienced a total of 236 arthritis-related STD events accounting for 9,197 STD workdays lost, or 3.0\% of all events and $3.5 \%$ of all STD workdays lost. The economic cost of arthritis-related STD workdays lost to the company, assuming an average employee salary and benefits of $\$ 50,000$ and 250 work days per year, is approximately $\$ 1.8$ million $(\$ 50,000 / 250 \times 9,197=\$ 1.8 \mathrm{M})$.

These results demonstrate that for a financial services company with a relatively young and predominantly female population, the major impact of arthritis is on lost worker productivity-presenteeism-rather than STD absenteeism. However, the dollar estimates calculated here are likely an overstatement since it is known that a greater percentage of the HRA participants in this company are female and older compared to HRA nonparticipants.

Muchmore et $\mathrm{al}^{34}$ reported on the prevalence and costs related to arthritis and associated joint disorder (AJD) among 230,000 employees of several companies in the United States. The overall prevalence of arthritis and AJD was
$15.5 \%$ for a population that was $56.6 \%$ female, with a mean age of 42.7 years. These authors noted that employees with AJDs had significantly higher healthcare and prescription drug, absenteeism, STD, long-term disability, and worker compensation costs, which totaled $\$ 1,802$. Productivity was $4 \%$ lower for workers with AJDs. However, productivity data was limited to a subset of employees in this study who were predominantly hourly workers in a "manufacturing-like environment." Productivity was measured as units processed per hour and annually. No further details were provided by the authors. Our study measured productivity for a variety of workers at all job levels in this financial services corporation.

A limitation of our study is that it is crosssectional. We are unable to determine the lifetime impact of arthritis in this population, since we do not have the date of onset of the disease. In addition, we are unable to determine the effect of severity of disease or its actual functional limitation on worker productivity. The HRA questionnaire was distributed in July and asked about work limitations during the previous 2 -week period. Therefore, we believe that impairment may be underestimated, since this is the summer season in the United States and many arthritis patients perceive improvement in their arthritis symptoms with warmer temperatures. ${ }^{36}$

The results found here suggest that those who have arthritis but do not receive medication or care have similar work loss compared to those without arthritis. As suggested earlier, those who do not take medication or receive care for their arthritis may have a less severe form of the condition compared to those who do receive care or medication. Companies would benefit from including questions on HRAs that identify those who receive medication or care for their self-reported health conditions as a surrogate measure for the severity of a given condition.

We noted earlier that this group of HRA participants is more likely to be female and older compared to the rest of this company's employee population. Furthermore, the group of employees who report receiving care or medication for their arthritis is also more likely to be female and older compared to employees 
with arthritis who do not receive care or medication. This may be due to the fact that women may be more likely to seek medical attention than men. While the analyses controlled for demographics, the extrapolation of the economic cost of productivity loss did not and thus may be overestimated.

The significantly reduced work-related productivity associated with arthritis is understandable for physically demanding jobs. In general, financial services jobs are not physically demanding except for the ubiquitous use of computers. Skills such as data input and typing clearly can be more difficult for an employee with significant arthritis. The finding that less than half of employees with arthritis are either under medical care and/or taking medication may indicate opportunities for significant improvement in the management of this chronic medical condition.

The implications of this study include support for the early identification of limitations in work function and appropriate treatment for arthritis, before the onset significantly impacts worker productivity. ${ }^{17}$ Self-management and behavioral disease management programs for arthritis can be successful and have a significant impact on function. ${ }^{37,38}$ The results also provide great impetus for employers and healthcare providers to address obesity, physical inactivity, and other health risks as significant contributing factors to the decrements in on-the-job productivity of employees with arthritis. ${ }^{39,40}$ An HRA that includes the WLQ is a valuable tool for disease management program administrators to use to evaluate the impact of a program on an employer's productivity, absenteeism, and STD costs. These costs are significant and are often not included in a disease management program's return-on-investment calculation.

This study provides a unique source of information on the impact of the most common form of arthritis on workplace productivity. Previously published studies of work function implications of arthritis have generally focused on rheumatoid arthritis. ${ }^{41}$ One limitation of the present study is that the data are specific to one employer. However, rather than manual labor, the types of jobs for this employer include cleri- cal as well as administrative roles, which are typical of a majority of the current US workforce. ${ }^{42}$

Arthritis is a relatively common, treatable chronic disease in the employed population, which has a significant impact on worker productivity. Disease management programs present an opportunity to enhance the quality of life of those patients and, at the same time, potentially limit the significant losses in on-thejob productivity for employers. ${ }^{43}$

\section{ACKNOWLEDGMENTS}

We wish to thank Debra Lerner, M.S., Ph.D. for her assistance with this study.

\section{REFERENCES}

1. Centers for Disease Control and Prevention. Prevalence of disabilities and associated health conditions among adults-United States, 1999. MMWR Morb Mortal Wkly Rep 2001;50:120-125.

2. Centers for Disease Control and Prevention. Prevalence of self-reported arthritis or chronic joint symptoms among adults-United States, 2001. MMWR Morb Mortal Wkly Rep 2002;51:948-950.

3. Centers for Disease Control and Prevention. Public health and aging: projected prevalence of self-reported arthritis or chronic joint symptoms among persons aged >65 years-United States, 2005-2030. MMWR Morb Mortal Wkly Rep 2003;52:489-491.

4. Yelin E, Cisternas MG, Pasta DJ, Trupin, L, Murphy L, Helmick CG. Medical care expenditures and earnings losses of persons with arthritis and other rheumatic conditions in the United States in 1997: total and incremental estimates. Arthritis Rheum 2004;50: 2317-2326.

5. Centers for Disease Control and Prevention. Healthrelated quality of life among adults with arthritis-behavioral risk factor surveillance system, 11 states, 1996-1998. MMWR Morb Mortal Wkly Rep 2000;49: 366-369.

6. Felson DT, Lawrence RC, Dieppe PA, et al. Osteoarthritis: new insights. Part 1 . The disease and its risk factors. Ann Intern Med 2000;133:635-646.

7. Healthy People 2010. Arthritis, osteoporosis, and chronic back conditions. Available at: www.healthypeople.gov/document/html/volume1/02arthritis.ht m. Accessed December 12, 2005.

8. Yelin E. The economics of osteoarthritis. In: Brandt K, Doherty M, Lohamndes LS, eds. Osteoarthritis. New York: Oxford University Press, 1998:23-30.

9. Manninen P, Riihimaki H, Heliovaara M, Makela P. Overweight, gender and knee osteoarthritis. Int J Obes Relat Metab Disord 1996;20:595-597. 
10. Felson DT, Zhang Y, Hannan MT, et al. Risk factors for incident radiographic knee osteoarthritis in the elderly: the Framingham Study. Arthritis Rheum 1997;40:728-733.

11. Leigh JP, Seavey W, Leistikow B. Estimating the costs of job related arthritis. I Rheumatol 2001;28: 1647-1654.

12. Mitchell JM. Work behavior after the onset of arthritis. Med Care 1991;29:362-376.

13. Yelin EH, Meenan R, Nevitt M, Epstein W. Work disability in rheumatoid arthritis: effects of disease, social and work factors. Ann Intern Med 1980;93: 551-556.

14. Yelin EH, Nevitt M, Epstein W. Toward an epidemiology of work disability. Milbank Memorial Fund Q 1980;58:386-415.

15. Yelin EH, Henke CJ, Epstein W. The work dynamics of the person with rheumatoid arthritis. Arthritis Rheum 1987;30:507-512.

16. Ricci JA, Stewart WF, Chee E, Leotta C, Foley K, Hochberg MC. Pain exacerbation as a major source of lost productive time in US workers with arthritis. Arthritis Rheum 2005;53:673-681.

17. Yelin E, Wanke LA. An assessment of the annual and long-term direct costs of rheumatoid arthritis: the impact of poor function and functional decline. Arthritis Rheum 1999;42:1209-1218.

18. Burton WN, Pransky G, Conti DJ, Chen C-Y, Edington DW. The association of medical conditions and presenteeism. J Occup Environ Med 2004;46:S38-S45.

19. Lerner D, Amick BC, Rogers WH, Malspeis S, Bungay K, Cynn D. The work limitations questionnaire: a self-administered instrument for assessing on-thejob work disability. Med Care 2001;39:72-85.

20. Lerner D, Reed JI, Massarotti G, Wester LM, Burke TA. The Work Limitations Questionnaire's validity and reliability among patients with osteoarthritis. I Clin Epidemiol 2002;55:197-208.

21. Burton WN, Chen CY, Conti DJ, Schultz AB, Pransky $\mathrm{G}$, Edington D. The association of health risks with on-the-job productivity. I Occup Environ Med 2005;47:769-777.

22. Musich S, Adams L, DeWolf G, Edington DW. A case study of 10-year health risk appraisal participation patterns in a comprehensive health promotion program. Am J Health Promot 2001;15:237-240.

23. Stein AD, Shakour SK, Zuidema RA. Financial incentives, participation in employer-sponsored health promotion, and changes in employee health and productivity: HealthPlus Health Quotient Program. J Occup Environ Med 2000;42:1148-1155.

24. Musich S, McDonald T, Hirschland D, Edington DW. Examination of risk status transitions among active employees in a comprehensive worksite health promotion program. J Occup Environ Med 2003;45:393-399.

25. Aldana SG, Greenlaw R, Diehl HA, Englert H, Jackson $\mathrm{R}$. Impact of the coronary health improvement project (CHIP) on several employee populations. I Occup Environ Med 2002;44:831-839.

26. Pelletier KR. A review and analysis of the clinical- and cost-effectiveness studies of comprehensive health promotion and disease management programs at the worksite: 1998-2000 update. Am J Health Promot 2001;16:107-116.

27. Lin EH, Katon W, Von Korff M, et al. Effect of improving depression care on pain and functional outcomes among older adults with arthritis: a randomized controlled trial. IAMA 2003;290: 2428-2429.

28. Burton WN, Chen CY, Conti DJ, Schultz AB, Edington DW. The association between health risk change and presenteeism change. I Occup Environ Med 2006;48:252-263.

29. Kessler RC, Greenberg PE, Mickelson KD, Meneades LM, Wang PS. The effects of chronic medical conditions on work loss and work cutback. J Occup Environ Med 2001;43:218-225.

30. Lawrence JS, Bremen JM, Bier F. Osteo-arthritis. Prevalence in the population and relationships between symptoms and x-rays changes. Ann Rheum Dis 1966;25:1-24.

31. Sokka T, Kankainen A, Hannonen P. Scores for functional disability in patients with rheumatoid arthritis are correlated at higher levels with pain scores than with radiographic scores. Arthritis Rheum 2000;43: 386-389.

32. Centers for Disease Control and Prevention. Impact of arthritis and other conditions on the healthcare system, United States, 1997. MMWR Morbid Mortal Wkly Rep 1999;48:349.

33. Felson DT, Zhang Y. An update on the epidemiology of knee and hip osteoarthritis with a view to prevention. Arthritis Rheum 1998;41:1343-1355.

34. Muchmore L, Lynch WD, Gardner HH. Prevalence of arthritis and associated joint disorders in an employed population and the associated healthcare, sick leave, disability and workers' compensation benefit cost and productivity loss for employers. I Occup Environ Med 2003;45:369-378.

35. Gabriel SE, Crowson CS, O'Fallon WM. Costs of osteoarthritis estimates from a geographically defined population. J Rheumatol 1995;45:23-25.

36. Redelmeier DA, Tversky A. On the belief that arthritis pain is related to the weather. Proc Natl Acad Sci USA 1996;93:2895-2896.

37. Lorig KR, Ritter PL, Laurent DD, Fries JF. Long-term randomized controlled trials of tailored-print and small-group arthritis self-management interventions. Med Care 2004;42:346-354.

38. Lorig KR, Mazonson PB, Holman HR. Evidence suggesting that health education for self-management in patients with chronic arthritis has sustained health benefits while reducing health care costs. Arthritis Rheum 1993;36:439-446.

39. Musich S, Faruzzi SD, Lu C, McDonald T, Hirshland D, Edington DW. Pattern of medical charges after quitting smoking among those with and without arthritis, allergies or back pain. Am J Health Promot 2003;18:133-142.

40. Mehrotra C, Chudy N, Thomas V. Obesity and physical inactivity among Wisconsin adults with arthritis. WMJ 2003;102:24-28. 
41. Cooper NJ. Economic burden of rheumatoid arthritis: a systematic review. Rheumatology 2000;39:28-33.

42. U.S. Department of Labor, Bureau of Labor Statistics. Employment and unemployment statistics. Available at: www.bls.gov/data/home.htm. Accessed July, 2005.

43. Chudy NE, Thomas V, Mehrotra C, Rumm PD. The Wisconsin Arthritis Program-a new partnership to reduce the leading cause of disability. WMJ 2003; 102:9-11.
Address reprint requests to: Dee W. Edington, Ph.D. Health Management Research Center University of Michigan 1027 East Huron St. Ann Arbor, MI 48104-1688

E-mail: dwe@umich.edu 


\section{This article has been cited by:}

1. Alyssa B. Schultz, Chin-Yu Chen, Dee W. Edington. 2009. The Cost and Impact of Health Conditions on Presenteeism to Employers. PharmacoEconomics 27:5, 365-378. [CrossRef]

2. Alyssa B. Schultz, Ph.D., Dee W. Edington, Ph.D.. Metabolic Syndrome in a Workplace: Prevalence, Co-Morbidities, and Economic ImpactMetabolic Syndrome in a Workplace: Prevalence, Co-Morbidities, and Economic Impact. Metabolic Syndrome and Related Disorders, ahead of print. [Abstract] [PDF] [PDF Plus]

3. Patricia B. Strasser, Diane L. Thomason, Lisa R. Lagowski. 2009. Sustaining a Healthy Work Force in the 21st Century- A Model for Collaborating Through Reciprocation. AAOHN Journal 56:12, 503-513. [CrossRef]

4. Wayne N. Burton, Chin-Yu Chen, Alyssa B. Schultz, Dee W. Edington. 2008. The Prevalence of Metabolic Syndrome in an Employed Population and the Impact on Health and Productivity. Journal of Occupational and Environmental Medicine 50:10, 1139-1148. [CrossRef]

5. Robin C Rager, Joseph A Leutzinger, Jeff A Hochberg, Wolf Kirsten, David H Chenoweth. 2008. Employee Disease Management in US and??Global Workplaces. Disease Management \& Health Outcomes 16:2, 87-94. [CrossRef]

6. A. Puig-Ribera, J. McKenna, N. Gilson. 2008. Measuring presenteeism in Catalan employees: linguistic adaptation and validation. International Journal of Workplace Health Management 1:3, 198-208. [CrossRef]

7. Alyssa B. Schultz, Dee W. Edington. 2007. Employee Health and Presenteeism: A Systematic Review. Journal of Occupational Rebabilitation 17:3, 547-579. [CrossRef]

8. Ronald Loeppke, Michael Taitel, Dennis Richling, Thomas Parry, Ronald C. Kessler, Pam Hymel, Doris Konicki. 2007. Health and Productivity as a Business Strategy. Journal of Occupational and Environmental Medicine 49:7, 712-721. [CrossRef] 